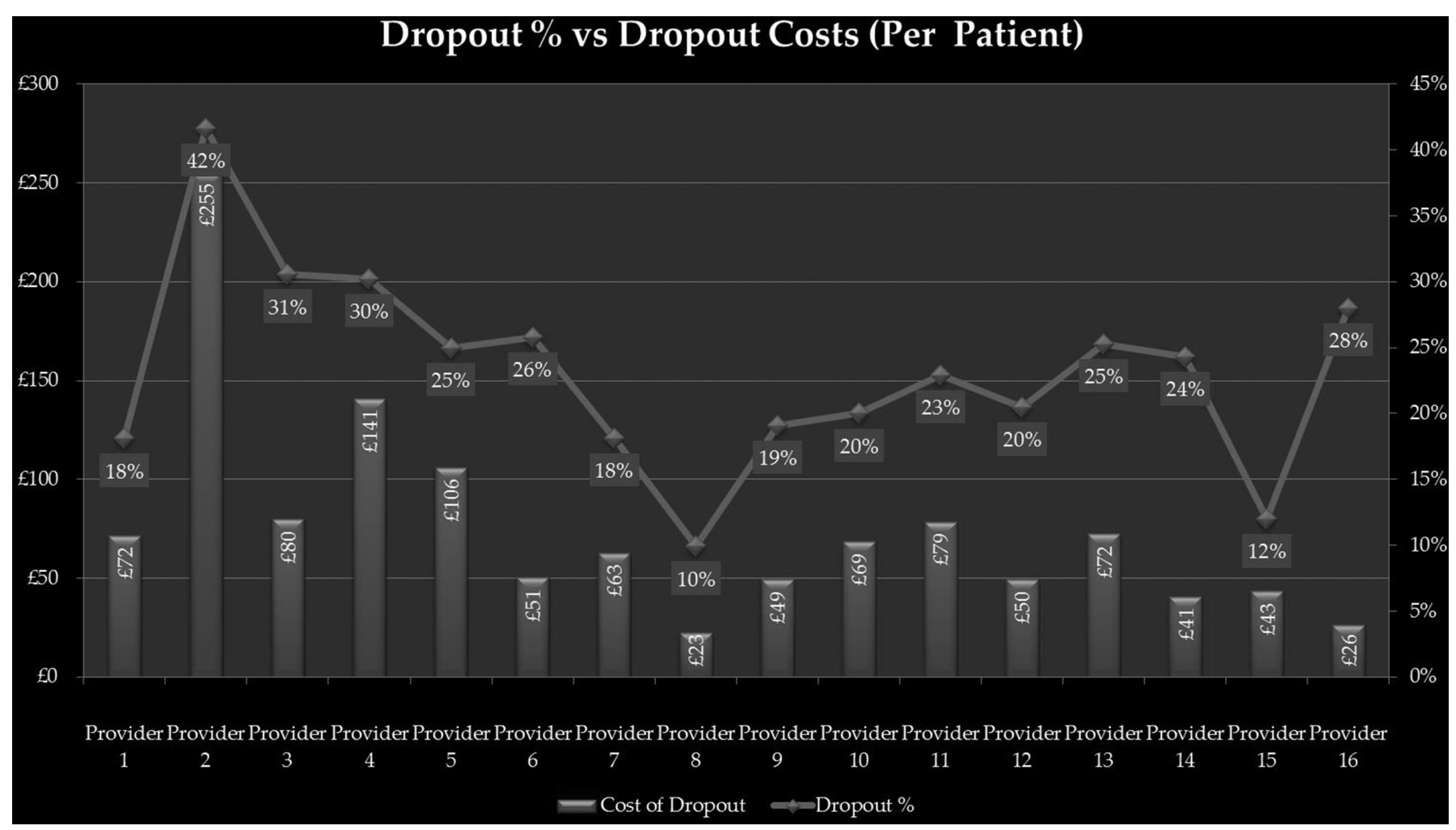

Abstract P122 Figure 1 Dropout\% vs Dropout Costs (Per Patient)

were assured actual costs and their identity would not be revealed.

Results

1. PR regionally serviced 3712 patients annually

2. Many providers total per patient costs were above the national tariff

3. Administration formed the highest share of providers total cost $(24 \%)$

4. Administration time per patient per course varied widely $(1-14 \mathrm{~h})$

5. There was a wide range of drop-out, $10-42 \%$, mean $23 \%$

6 . The mean $(£ 76)$ and range $(£ 23-£ 255)$ of drop-out cost per patient was high, rising at an ever increasing rate for every dropout (Figure)

7. Both larger patient numbers and rolling programmes were associated with higher per patient cost, the latter accountable to higher admin costs surpassing savings in exercise session costs.

8. Inconsistent reporting of clinical outcome data by providers.

Conclusion Our analysis demonstrates significant variation in the makeup of providers' individual costs, with the majority of the variation between providers' total cost per patient attributed to dropouts. Administration and drop-out were the greatest contributory factors to higher service costs. Higher cost was associated with larger patient numbers and rolling programmes.

Discussion Insufficient clinical outcome data were received to make any meaningful comparison of cost with outcome. Further work in this area is therefore required. Providers expected that providing services for larger numbers of patients and using rolling programmes would have lower costs, but the reverse was true. Administration costs for PR are very significant and may frequently be the key driver behind cost differences.

\section{P123 THE BENEFITS OF PULMONARY REHABILITATION (PR) IN INTERSTITIAL LUNG DISEASE (ILD): OBSERVATIONS FROM OXFORDSHIRE'S MIXED RESPIRATORY DISEASE, COMMUNITY BASED PR PROGRAMME}

${ }^{1} \mathrm{R}$ Lardner, ${ }^{2} \mathrm{~S}$ Bolton, ${ }^{3} \mathrm{R}$ Hoyles. ${ }^{1}$ Oxford University Hospitals NHS Trust, Oxford, UK; ${ }^{2}$ Oxford Health NHS Foundation Trust, Oxford, UK; ${ }^{3}$ Oxford Centre for Respiratory Medicine, Oxford, UK

\subsection{6/thoraxjnl-2014-206260.264}

Introduction The benefits of increased exercise capacity and health related quality of life after PR are well documented in chronic obstructive pulmonary disease (COPD). Interest is growing in whether other respiratory diseases benefit from PR interventions. Limited research is available to demonstrate benefit to patients with ILD (Holland et al., 2008). No published studies examine the relative performance of ILD patients in a PR programme compared with a mixed disease cohort.

Objective To establish whether ILD patients benefit from participation in an established PR programme.

Methods Pre- and post-PR data for patients with ILD who took part in a 6-week PR programme compliant with BTS guidelines (Bolton et al., 2013), were examined alongside similar data for all patients who had participated in the PR programmes over an 18 month period.

Results Data was available for 21 patients with ILD, and 344 patients with other respiratory diseases. Median MRC grade of both groups of patients was 4 . Mean baseline lung function of ILD patients was $\mathrm{FEV}_{1} 2.06 \quad(84.6 \%$ predicted), FVC 2.59 (82.81\% predicted), $\mathrm{FEV}_{1} / \mathrm{FVC} 78.37, \mathrm{TL}_{\mathrm{CO}} 46 \%$ predicted. Incremental Shuttle Walk Test (ISWT) and St Georges Respiratory Questionnaire (SGRQ) data for ILD patients, and the whole cohort is shown in the attached table. 
Abstract P123 Table 1 Summary of mean values Pre-PR, Post-PR and change after PR for ISWT and SGRQ

\begin{tabular}{llll}
\hline & & ILD patients $(\mathbf{n}=21)$ & Whole cohort $(\mathbf{n}=344)$ \\
\multirow{4}{*}{ ISWT } & Pre-PR & 197.62 & 202.48 \\
& Post-PR & 254.29 & 266.25 \\
\multirow{4}{*}{ SGRQ symptoms } & Change & 56.67 & 63.77 \\
& Pre-PR & 50.48 & 60.77 \\
& Post-PR & 39.15 & 55.23 \\
& Change & 11.90 & 5.54 \\
SGRQ activity & Pre-PR & 69.14 & 70.34 \\
& Post-PR & 66.70 & 66.61 \\
& Change & 2.90 & 3.71 \\
SGRQ Impact & Pre-PR & 34.95 & 39.66 \\
& Post-PR & 34.55 & 34.44 \\
& Change & 1.40 & 5.22 \\
SGRQ Total & Pre-PR & 48.00 & 52.42 \\
& Post-PR & 44.90 & 47.71 \\
& Change & 3.85 & 4.71 \\
\hline
\end{tabular}

Discussion Examination of data available demonstrates that patients with ILD achieve the minimum important difference of the ISWT $(>47.5 \mathrm{~m})$ and were close to achieving the minimum important difference of the SGRQ $(>4)$. ILD patients have a greater benefit in terms of reduction in symptoms as measured by SGRQ, than the cohort as a whole. Limitations to generalisation of conclusions due to small sample size are acknowledged. Conclusion ILD patients who completed a 6-week community based, PR programme within a mixed respiratory disease cohort demonstrate a clinically significant improvement in exercise capacity and make gains in health related quality of life.

\section{REFERENCES}

1 Bolton C, Bevan-Smith E, Blakey J, et al. British Thoracic Society guideline on pulmonary rehabilitation in adults. Thorax. 2013;68:ii1-ii130

2 Holland A, Hill C, Conron M, Munro P, McDonald C. Short term improvement in exercise capacity and symptoms following exercise training in interstitial lung disease. Thorax, 2008;63:549-554

\section{P124 DO WE NEED A PRACTICE INCREMENTAL SHUTTLE WALK TEST FOR PATIENTS WITH INTERSTITIAL LUNG DISEASE REFERRED FOR PULMONARY REHABILITATION?}

${ }^{1} \mathrm{~V}$ Johnson-Warrington, ${ }^{2} \mathrm{~L}$ Sewell, ${ }^{2} \mathrm{M}$ Steiner, ${ }^{2} \mathrm{M}$ Morgan, ${ }^{2} \mathrm{~S}$ Singh. ${ }^{1}$ University Hospitals Coventry and Warwickshire, Coventry, UK; ${ }^{2}$ Centre for Exercise and Rehabilitation Science, University Hospitals of Leicester NHS Trust, Leicester, UK

\subsection{6/thoraxjnl-2014-206260.265}

Background Patients with Interstitial Lung Disease (ILD) are more frequently being referred to Pulmonary Rehabilitation (PR) where exercise capacity is measured, often by an Incremental Shuttle Walk Test (ISWT). These patients are frequently limited by severe dyspnoea and exertional desaturation. Available guidelines ${ }^{1}$ suggest two ISWTs are needed, however this can be time consuming.

Objective To investigate if a practice ISWT is needed for patients with ILD referred to PR.

Methods Patients with ILD recorded on our PR database, who attended a PR assessment and performed 2 ISWTs, ${ }^{1}$ were selected. Patients were included if they had 2 recorded ISWTs using the same oxygen prescription and mobility aid (if any) between tests and provided written consent. Hospital notes were retrieved, diagnosis confirmed and relevant data extracted and validated.

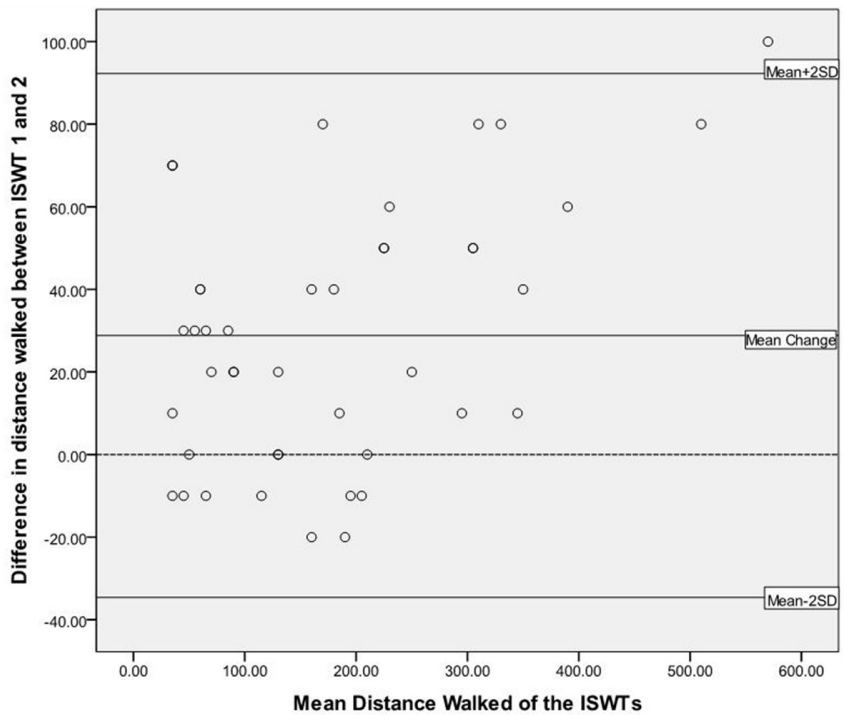

Abstract P124 Figure 1 Bland-Altman plot showing agreement between the two ISWTs

Results 43 patients (24 male) were included, 18 with Idiopathic Pulmonary Fibrosis. Participants were mean (SD) 72.17(10.54) years, Forced Vital Capacity was 2.28(0.87)1 [77.24(25.46)\% predicted], Transfer factor for the Lung for Carbon Monoxide $3.60(1.07) \mathrm{ml} / \mathrm{mmHg}[44.79(12.80) \%$ predicted], median (interquartile range) Medical Research Council dyspnoea grade 3.5 (3-4) and 29 used oxygen therapy.

Participants achieved $165.12(123.89) \mathrm{m}$ on ISWT1 with post$\mathrm{SaO}_{2} 87.86(5.86) \%$, heart rate 97.03(14.71), Borg breathlessness 4(3-5) and Rated Perceived Exertion (RPE) 13(11.25-15). There was a change of $28.84(31.71) \mathrm{m}$ between the two ISWTs ( $p<0.001) ; 72.1 \%$ of patients walked further on their second ISWT. Backward linear regression only explained $42 \%$ of this variance $\left(R^{2}\right.$. 426).

For those who did not improve, ISWT1 was $\leq 210 \mathrm{~m}$. BlandAltman plot showed good agreement between the ISWTs, however the limits of agreement were wide. There was a significant difference in Endurance Shuttle Walk Test levels when calculated at $85 \%$ of $\mathrm{VO}_{2}$ peak as estimated from ISWT1 and ISWT2 $(\mathrm{p}<0.001)$.

Conclusions For patients with ILD, we have shown that there are significant differences between the first and second ISWT and therefore a practice ISWT is needed in order to accurately assess exercise capacity, prescribe an exercise programme and ensure services and interventions are correctly evaluated. We were unable to predict those who did not need to complete 2 ISWTs.

\section{REFERENCE}

1 Singh et al. Development of a shuttle walking test of disability in patients with chronic airways obstruction. Thorax.1992;47:1019-1024

\section{P125 THE IRISH LUNG FIBROSIS ASSOCIATION'S 2000 STEPS A DAY CHALLENGE: A PILOT STUDY TO EVALUATE A NOVEL HOME EXERCISE PROGRAMME FOR LUNG FIBROSIS PATIENTS}

${ }^{1} \mathrm{~N}$ Cassidy, ${ }^{2} \mathrm{~A}$ Byrne, ${ }^{2} \mathrm{D}$ Danaher, ${ }^{2} \mathrm{JJ}$ Egan. ${ }^{1}$ Irish Lung Fibrosis Association, Dublin, Ireland; ${ }^{2}$ Mater Misericordiae University Hospital, Dublin, Ireland

10.1136/thoraxjnl-2014-206260.266 